\title{
Choroidal Thickness Evaluation in a Transfusion-Dependent Beta-Thalassemia Greek Population
}

This article was published in the following Dove Press journal: Clinical Ophthalmology

\author{
Foteini Tsapardoni' \\ Olga E Makri (iD)' \\ Vasileios Lazaris (iD ${ }^{2}$ \\ Vassiliki Labropoulou ${ }^{2}$ \\ Spyridon Lygeros ${ }^{3}$ \\ Stylianos Mastronikolis (D) \\ Alexandra Kouraklis ${ }^{2}$ \\ Argiris Symeonidis (iD) ${ }^{2}$ \\ Constantinos D Georgakopoulos (D) \\ 'Department of Ophthalmology, \\ University Hospital of Patras, Patras, \\ Greece; ${ }^{2}$ Hematology Division, \\ Department of Internal Medicine, \\ University Hospital of Patras, Patras, \\ Greece; ${ }^{3}$ Medical School, University of \\ Patras, Patras, Greece
}

Purpose: To evaluate choroidal thickness in a group of beta-thalassemia patients as assessed by enhanced depth imaging optical coherence tomography.

Patients and Methods: This single-center, observational study involved transfusiondependent beta-thalassemia (TD- $\beta$-thal) patients and healthy controls. One eye of each participant was included in the study. Submacular and peripapillary choroidal thickness, as well as central macular thickness and retinal nerve fiber layer thickness, were evaluated.

Results: Thirty-eight TD- $\beta$-thal patients (mean age $42 \pm 10.7$ years) and 22 healthy controls (mean age $40.3 \pm 10.2$ years) were included in the study. Subfoveal choroidal thickness was $297.4 \pm 74.5 \mu \mathrm{m}$ in the patient group and $358.4 \pm 71.4 \mu \mathrm{m}$ in the control group ( $\mathrm{p}=0.003$ ). Overall, in the submacular area, the choroid was found to be significantly thinner in the betathalassemia population compared to controls in all evaluated points, except for the spot located $1500 \mu \mathrm{m}$ nasally to the fovea $(\mathrm{p}=0.093)$. In the peripapillary area, choroidal thickness was also significantly lower in the thalassemic population compared to the controls (nasal $\mathrm{p}=0.033$, temporal $\mathrm{p}=0.01$, superior $\mathrm{p}=0.01)$, except for the inferior quadrant $(\mathrm{p}=0.191)$. We did not observe statistically significant differences in the retinal nerve fiber layer thickness and the central macular thickness between the two groups $(\mathrm{p}=0.658$ and $\mathrm{p}=0.276$, respectively). No correlations with hemoglobin, serum ferritin or iron levels emerged. Patients with the intermediate subtype appeared to have significantly thinner choroids than the ones with thalassemia major.

Conclusion: Our findings suggest that choroidal thickness in the submacular and peripapillary area is significantly reduced in thalassemic patients, compared to healthy individuals. Choroidal thinning in beta-thalassemia possibly reflects the effect of chronic anemia and underlying hemodynamic changes on choroidal tissue.

Keywords: central macular thickness, retinal nerve fiber layer thickness, iron chelation treatment, erythrocyte transfusion

\section{Introduction}

Beta-thalassemia is the most predominant hemoglobinopathy and genetic defect in Greece, with the prevalence of heterozygous carriers in the general population being estimated as high as $7.5 \%{ }^{1}$ It is characterized by impaired synthesis of hemoglobin beta chains with clinical phenotypes varying from completely asymptomatic individuals to severe microcytic hypochromic chronic anemia with growth disturbance and multiple organ dysfunction.
Correspondence: Constantinos D Georgakopoulos

Ophthalmology Department, University Hospital of Patras, Patras, GR 26504, Greece Tel +30 2610999262

$\mathrm{Fax}+302610993994$

Email cgeorg@upatras.gr 
Depending on the severity of anemia, red blood cell (RBC) transfusions may regularly be required to improve survival in beta-thalassemia major ( $\beta$-TM) and intermedia $(\beta$-TI). In transfusion-dependent beta-thalassemia (TD- $\beta$ thal) patients, lifelong blood transfusions are complicated by iron overload that burdens major organs, such as the heart and liver and render essential the administration of iron chelators, such as deferoxamine which are known to cause ocular toxicity. ${ }^{2}$

Several ocular findings, including dry eye, lens opacities, shorter axial length, venous tortuosity, retinal pigment epithelium (RPE) degeneration and optic neuropathy have been associated with beta-thalassemia. ${ }^{3,4}$ It is often uncertain to what extent these abnormalities are the result of chronic anemia itself which can per se induce retinal abnormalities or indicators of iron chelators' toxicity. ${ }^{2}$

The choroid represents the principal oxygen and nutrients' supply source for the outer retina. Notably, it accounts for $95 \%$ of all ocular blood flow ${ }^{5}$ and determines a crucial role in thermoregulation of the retina, secretion of growth factors and disposal of retinal metabolism products through circulation. ${ }^{6}$ Previously available tools for choroidal imaging such as indocyanine green angiography, laser Doppler flowmetry and ultrasound may reveal vascular and anatomic alterations but the advent of enhanced depth imahing optical coherence tomography (EDI-OCT) has permitted direct visualization and anatomical assessment of choroidal tissue and layers in a cross-sectional fashion. ${ }^{7}$ Choroidal thickness, which has recently been thoroughly investigated, is influenced among others by age, refractive status, and axial length, ${ }^{7}$ while diurnal variations have also been observed. ${ }^{8}$

Hemodynamic changes that occur in TD- $\beta$-thal patients could result in alterations in a highly vascularized tissue such as the choroid. Previous studies focusing on either $\beta-\mathrm{TM}^{9,10}$ or thalassemic trait subjects, ${ }^{11}$ concluded that subfoveal choroidal thickness was in fact decreased in beta-thalassemia. Our study aimed to evaluate posterior segment structures and determine the possible effect of beta-thalassemia, on choroidal thickness in the wider submacular area, as well as the peripapillary area, in TD- $\beta$-thal, including both $\beta$-TM and $\beta$-TI patients.

\section{Patients and Methods}

This prospective, observational, single-center study took place at the Ophthalmology Department in association with the Hematology Department of the University Hospital of Patras in South Western Greece, between
May 2019 and April 2020. All procedures of this study were in accordance with the tenets of the Declaration of Helsinki. The study protocol was approved by the University Hospital of Patras Ethics Committee (reference number 9894/20-5-2016) prior to initiation of the study.

Inclusion criteria in the study group were individuals diagnosed with $\beta$-TM or $\beta$-TI, who underwent regular RBC transfusions. No restrictions were applied regarding the type of iron chelation treatment. The control group consisted of 22 age- and sex-matched healthy volunteers who were randomly selected after a general screening examination at the ophthalmology outpatient clinic.

Exclusion criteria included any history of previous intraocular surgery or laser therapy, ocular trauma, glaucoma, uveitis, amblyopia, strabismus and retinal abnormalities detected on ophthalmological examination, as well as other chronic systemic disease, such as systemic hypertension, diabetes mellitus, neurodegenerative disorders, or connective tissue disease and cigarette smoking. ${ }^{12}$ Furthermore, to minimize the effect of axial length, patients with refractive error exceeding 3 diopters were excluded. Individuals who did not consent to the procedures of the study, could not maintain proper fixation or provide proper image quality due to severe media opacities or ocular surface disease were also excluded.

After receiving written informed consent, a detailed medical history was taken for all enrolled subjects. Hemoglobin and ferritin levels were evaluated in all patients on the day of the examination. All participants underwent a complete ophthalmic examination, including refraction and $\log$ MAR best corrected visual acuity (BCVA), slit lamp examination, intraocular pressure (IOP) measurement by Goldmann applanation tonometry and dilated fundus examination.

Spectral-domain optical coherence tomography (Heidelberg Engineering, SD-OCT, software version 5.3, Heidelberg, Germany) using the enhanced depth imaging (EDI) mode, which allows for choroidal depiction and reproducible measurement of choroidal thickness, ${ }^{13}$ was performed in the right eye of all subjects. Eye-tracking was used to ensure image quality and improve acquisition time. Moreover, to enhance choroidal visualization and reduce noise, automatic real-time averaging was applied. The OCT scanning position was precisely matched with the scanning laser ophthalmoscope fundus image. Three single $30^{\circ}(8.7 \mathrm{~mm}$ length) line macular scans, centered on the fovea, were acquired in both the horizontal and vertical meridian for each participant. The fovea was manually 

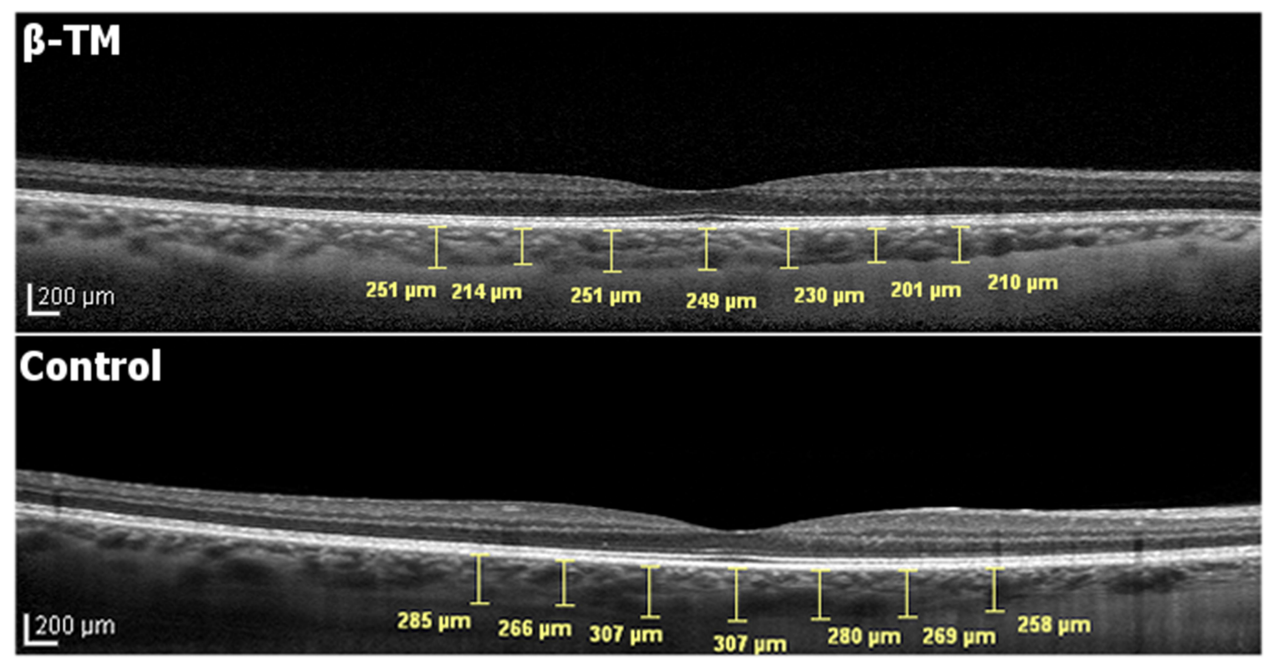

Figure I Representative EDI-OCT images. Horizontal macular line scans obtained from a $\beta$-TM patient (top) and a healthy control (bottom). Choroidal thickness was measured subfoveally as well as at 500,1000 and $1500 \mu$ m locations nasally and temporally to the fovea.

Abbreviations: $\beta$-TM, beta-thalassemia major; EDI-OCT, enhanced depth imaging optical coherence tomography

identified and was defined as the concave area in the center of the macula, without inner retina layers, with a slight thickening of the ellipsoid zone. For peripapillary choroidal imaging, the standard protocol for retinal nerve fiber layer (RNFL) assessment was used. Three $360^{\circ}$ circular scans of $3.4 \mathrm{~mm}$ diameter, centered on the optic disc were received. Measurements of central macular thickness (CMT) and RNFL thickness were also recorded.

All OCT scans were assessed for image centration and quality. Scans with poor reproducibility, decentered images or images of a signal-to-noise ratio $<20 \mathrm{~dB}$ were excluded. All measurements were obtained by an experienced and masked physician (FT) between 9 am and 12 am, to minimize diurnal fluctuation of choroidal thickness. ${ }^{8}$ All subjects were examined in the same room under the same environmental and lighting conditions. ${ }^{14}$ Participants were asked to abstain from caffeine consumption in the morning of the examination. ${ }^{15}$ Examination was conducted before patients' admission for scheduled RBC transfusion to avoid possible choroidal thickness changes due to hemodynamic alterations during or after red blood cell transfusion.

Images were converted to a 1:1 pixel ratio for analysis by a blinded investigator (OM). The standard Heidelberg Explorer software was employed for image processing. CMT and RNFL thickness measurements were automatically provided. Choroidal thickness measurements were conducted subfoveally and at $500 \mu \mathrm{m}$ intervals, centrifugally from the fovea in all four sectors. More specifically, calipers were positioned to mark the areas of interest manually using the incorporated Spectralis software at 500, 1000 and $1500 \mu \mathrm{m}$ nasally, temporally, superiorly and inferiorly to the fovea (Figure 1). The peripapillary choroidal thickness was evaluated in a superior, inferior, temporal and nasal location. Since no software for automated choroidal thickness measurement is available, measurements were performed manually as the perpendicular distance from the hyperreflective outer border of the retinal pigment epithelium/Bruch membrane complex to the inner scleral border. The boundaries' delineation was performed using a built-in ruler tool by two blinded experienced observers. The average measurement value of 3 obtained scans was used for statistical analysis.

\section{Statistical Analysis}

Statistical analysis was performed with the assistance of the SPSS statistical software (SPSS for Windows, version 23.0; SPSS, Inc., Chicago, IL, USA). All data were expressed as mean \pm standard deviation. The normality of the data was assessed using the Kolmogorov-Smirnov test. When $p>0.05$ the null hypothesis, that data are taken from normal distributed population, is accepted.

Comparison of obtained values between the thalassemia and control group was conducted, using the independent samples $t$-test for continuous variables and the MannWhitney $U$-test for nonparametric data.

Multivariable linear regression analysis, with the stepwise method, was conducted in the beta-thalassemia group 
Table I Demographic Characteristics of the 2 Groups

\begin{tabular}{|c|c|c|c|}
\hline & Beta-Thalassemia & Control & $p$ \\
\hline Number & 38 & 22 & \\
\hline Age, years (mean \pm SD) & $42 \pm 10.7$ & $40.3 \pm 10.2$ & $0.550 *$ \\
\hline $\begin{array}{l}\text { Sex } \\
\qquad \text { Male, n (\%) } \\
\text { Female, n (\%) }\end{array}$ & $\begin{array}{l}15(39.5) \\
23(60.5)\end{array}$ & $\begin{array}{l}12(54.5) \\
10(45.5)\end{array}$ & $0.258 \dagger$ \\
\hline $\begin{array}{r}\text { BCVA, logMAR } \\
\text { Median (range) }\end{array}$ & $0(0-0.3)$ & $0(0-0)$ & $0.187 \ddagger$ \\
\hline $\begin{array}{l}\text { Spherical equivalent, Diopters } \\
\text { Median (range) }\end{array}$ & $0(-3.0$ to +2.5$)$ & $0(-3.0$ to +1.5$)$ & $0.704 \ddagger$ \\
\hline $\begin{array}{l}\text { Intraocular pressure, } \mathbf{m m H g} \\
\text { Median (range) }\end{array}$ & $13(10-18.5)$ & $13(11-17)$ & $0.390 \ddagger$ \\
\hline
\end{tabular}

Notes: *Independent samples $t$-test; ${ }^{\dagger}$ Chi-square test; ${ }^{\ddagger}$ Mann-Whitney $U$-test.

in order to evaluate possible correlations of CMT, SFCT and RNFL thickness with various independent variables such as age, sex, body weight, type of chelation therapy administered at the time of inclusion in the study, type of beta-thalassemia, years of transfusion dependency, levels of hemoglobin, serum ferritin values, iron and C-reactive protein levels, possible treatment with antiplatelets, history of splenectomy or hypothyroidism and imaging data depicting the severity of iron load in the liver and heart, estimated by $\mathrm{T} 2 *$-weighted magnetic resonance imaging. We also included in the multivariable regression analysis the axial length and the spherical equivalent.

For all statistical analyses performed, differences were considered statistically significant at 2-tailed $p$ value of $<0.05$.

A power analysis was performed and the minimum sample size required in this study was calculated as at least 35 participants in the study group and at least 17 healthy volunteers with significance level being set to $<0.05$ and statistical power 0.9 . The sample size calculation was conducted using the GPower software (version 3.1 ) and was based on the results of a previous study. ${ }^{16}$

\section{Results}

The present study included 60 eyes of 60 participants. Complete data were collected for 38 patients (15 males, 23 females) with $\beta$-TM or $\beta$-TI and 22 healthy controls (12 males, 10 females). Demographic data of the two groups are summarized in Table 1 . The mean age was $42 \pm 10.7$ years for the thalassemia patients and $40.3 \pm 10.2$ years for controls. The two groups did not differ significantly with respect to age and $\operatorname{sex}(\mathrm{p}=0.55$ and $\mathrm{p}=0.58$, respectively). Similarly, no significant differences were recorded as far as BCVA, IOP and refractive status are concerned between the two study groups $(p=0.187, p=0.390$ and $p=0.704$, respectively).

The clinical characteristics of the beta-thalassemia group are presented in Tables 2-4. In this group 60.5\% of the patients were classified as $\beta$-TM and $39.5 \%$ as $\beta$ TI. The patients examined had been receiving $\mathrm{RBC}$ transfusions for a mean of $28 \pm 12$ years. Their mean hemoglobin value was $9.4 \pm 0.7 \mathrm{~g} / \mathrm{dl}$ and the median ferritin value was $1106 \mathrm{ng} / \mathrm{mL}$ (range 117 to $15719 \mathrm{ng}$ / $\mathrm{mL}$ ). As far as iron chelation treatment is concerned, at the time of the examination 12 patients were under deferasirox, 6 under deferoxamine, one under deferiprone, while 13 were receiving a combination regimen of deferoxamine plus deferiprone, and the remaining 6 deferoxamine plus deferasirox.

Table 5 shows the CMT, RNFL and choroidal thickness subfoveally and at the selected locations in the two groups. There was no statistically significant difference in CMT between beta-thalassemia patients and healthy volunteers $(\mathrm{p}=0.276)$.

The choroidal thickness of thalassemic patients was significantly reduced subfoveally, compared to healthy participants $(p=0.003)$. Furthermore, in the patient group the choroid was significantly thinner at 11 out of the 12 evaluated peripheral points of the posterior pole, compared to healthy controls. No statistically significant difference in choroidal thickness was observed between the two groups at $1500 \mu \mathrm{m}$ nasally. $(\mathrm{p}=0.093)$. 
Table 2 Characteristics of the Beta-Thalassemia Group

\begin{tabular}{|c|c|}
\hline Characteristics & \\
\hline \multicolumn{2}{|c|}{ Type of Beta-Thalassemia } \\
\hline Major, n (\%) & $23(60.5)$ \\
\hline Intermedia, n (\%) & $15(39.5)$ \\
\hline Years of transfusion & $28 \pm 12$ \\
\hline Body Weight (Kg) & $63.3 \pm 11$ \\
\hline $\mathrm{Hb}(\mathrm{g} / \mathrm{dl})$ & $9.4 \pm 0.7$ \\
\hline Platelets $\left(\times 10^{3} / \mathrm{mL}\right)$ & $373.5 \pm 199$ \\
\hline Bilirubin (mg/dl) & $2.1 \pm 1$ \\
\hline LDH (IU/mL) & $265.4 \pm 122.6$ \\
\hline Ferritin $(\mathrm{ng} / \mathrm{mL})$ & $2183.8 \pm 3024.9$ \\
\hline $\mathrm{Fe}(\mu \mathrm{g} / \mathrm{mL})$ & $213.4 \pm 47.7$ \\
\hline TIBC $(\mu \mathrm{g} / \mathrm{mL})$ & $288.9 \pm 104.9$ \\
\hline Tf Sat (\%) & $0.8 \pm 0.2$ \\
\hline CRP (mg/dl) & $1.3 \pm 1.9$ \\
\hline LIC (Fe mg/g) & $9.6 \pm 11.5$ \\
\hline T2* Liver (ms) & $8.6 \pm 8.9$ \\
\hline T2* Cardiac (ms) & $41.8 \pm 17.9$ \\
\hline LVEF (\%) & $62.8 \pm 7.8$ \\
\hline Splenomegaly, n (\%) & $8(2 I . I)$ \\
\hline Splenectomy, n (\%) & $18(47.4)$ \\
\hline
\end{tabular}

Abbreviations: $\mathrm{Hb}$, hemoglobin; $\mathrm{LDH}$, lactate dehydrogenase; $\mathrm{Fe}$, iron; TIBC, total iron binding capacity; Tf Sat, transferrin saturation; CRP, C reactive protein; LIC, liver iron concentration; T2* Liver and $\mathrm{T}^{*}$ Cardiac, $\mathrm{T}^{*}$ weighted magnetic resonance imaging values correlate with iron load in the liver and heart; LVEF, left ventricle ejection fracture.

Table 3 Comorbidities of the Beta-Thalassemia Group

\begin{tabular}{|l|l|}
\hline Condition & \\
\hline Heart Disease & \\
\hline Afib, n (\%) & $5(13.2)$ \\
PHTN, n (\%) & $2(5.3)$ \\
HF, n (\%) & $1(2.6)$ \\
\hline Thromboses, n (\%) & $2(5.3)$ \\
\hline Hypothyroidism, n (\%) & $13(34.2)$ \\
\hline
\end{tabular}

Abbreviations: Afib, atrial fibrillation; PHTN, pulmonary hypertension; HF, heart failure.

The average RNFL thickness values did not differ significantly between the two groups $(\mathrm{p}=0.658)$. However, the peripapillary choroid, evaluated at points
Table 4 Medications Administered in the Beta-Thalassemia Group

\begin{tabular}{|c|c|}
\hline Treatment & \\
\hline \multicolumn{2}{|c|}{ Chelation Treatment (at the Time of Inclusion in the Study) } \\
\hline Deferasirox, n (\%) & $12(31.6)$ \\
\hline Deferoxamine, $\mathrm{n}(\%)$ & $6(15.8)$ \\
\hline Deferoxamine and Deferiprone, $\mathrm{n}(\%)$ & $13(34.2)$ \\
\hline Deferiprone, n (\%) & I (2.6) \\
\hline Deferoxamine and Deferasirox, $\mathrm{n}(\%)$ & $6(15.8)$ \\
\hline $\mathrm{HU}, \mathrm{n}(\%)$ & $9(23.7)$ \\
\hline Anti-PLT, n (\%) & $14(36.8)$ \\
\hline HRT, n (\%) & $15(39.5)$ \\
\hline
\end{tabular}

Abbreviations: HU, hydroxyurea; Anti-PLT, antiplatelet drugs; HRT, hormone replacement therapy.

located temporally, nasally and superiorly was significantly thinner among beta-thalassemia patients, in comparison to healthy individuals $(\mathrm{p}=0.010, \mathrm{p}=0.033$ and $\mathrm{p}=0.010$, respectively). Nevertheless, there was no significant difference at the inferior peripapillary area between the 2 groups $(\mathrm{p}=0.191)$.

\section{Multivariable Linear Regression Analysis}

Multivariable linear regression analysis in the betathalassemia group revealed that CMT correlated significantly with age $(\mathrm{p}<0.001)$, weight $(\mathrm{p}=0.003)$ and axial length $(\mathrm{p}=0.043)\left(F=8.883, R^{2}=0.506\right)$. More precisely, CMT increased significantly with age, weight and axial length.

The RNFL thickness correlated significantly negatively with the spherical equivalent $(\mathrm{p}<0.026)\left(F=5.564, R^{2}=\right.$ 0.166).

Finally, the SFCT was found to be significantly associated with the type of beta-thalassemia $(\mathrm{p}=0.007)$ and the presence of hypothyroidism $(\mathrm{p}=0.032)\left(F=6.352, R^{2}=\right.$ 0.320 ). More precisely, patients with $\beta$-TI had significantly lower SFCT compared to patients with homozygous betathalassemia. Furthermore, significantly higher SFCT was found in patients with a history of hypothyroidism.

\section{Discussion}

In the present study, we proceeded based on the assumption that evaluation of the choroid could provide more information on the ocular blood supply status in thalassemic patients. We mainly demonstrated that TD- $\beta$-thal patients have significantly thinner choroids than healthy 
Table 5 Comparison of the Central Macular Thickness (CMT), Retinal Nerve Fiber Layer (RNFL) Thickness and Choroidal Thickness (CT) Subfoveally (SFCT) and at the Selected Locations

\begin{tabular}{|c|c|c|c|}
\hline & $\begin{array}{l}\text { Beta-Thalassemia } \\
(n=38)\end{array}$ & $\begin{array}{l}\text { Control } \\
(n=22)\end{array}$ & $p$ \\
\hline CMT $(\mu \mathrm{m})$ & $224.7 \pm 17.9$ & $229.7 \pm 15.4$ & $0.276^{*}$ \\
\hline RNFL $(\mu \mathrm{m})$ & $102.1 \pm 10.9$ & $100.9 \pm 8.7$ & $0.658^{*}$ \\
\hline SFCT $(\mu \mathrm{m})$ & $297.4 \pm 74.5$ & $358.4 \pm 71.4$ & $0.003^{*}$ \\
\hline $500 \mu \mathrm{m}$ temporal CT $(\mu \mathrm{m})$ & $291 \pm 67.9$ & $344.8 \pm 78.8$ & $0.007^{*}$ \\
\hline $1000 \mu \mathrm{m}$ temporal CT $(\mu \mathrm{m})$ & $279.5 \pm 72.3$ & $335.4 \pm 69.1$ & $0.005^{*}$ \\
\hline $1500 \mu \mathrm{m}$ temporal CT $(\mu \mathrm{m})$ & $261.8 \pm 67.1$ & $327.5 \pm 65.3$ & $<0.00 I^{*}$ \\
\hline $500 \mu \mathrm{m}$ nasal $\mathrm{CT}(\mu \mathrm{m})$ & $292.2 \pm 76.9$ & $336.09 \pm 70.99$ & $0.032^{*}$ \\
\hline $1000 \mu \mathrm{m}$ nasal CT $(\mu \mathrm{m})$ & $273.4 \pm 80.8$ & $320.9 \pm 63.1$ & $0.021 *$ \\
\hline I500 $\mu \mathrm{m}$ nasal CT $(\mu \mathrm{m})$ & $252.2 \pm 82.6$ & $291.5 \pm 68.4$ & $0.093 \dagger$ \\
\hline $500 \mu \mathrm{m}$ superior $\mathrm{CT}(\mu \mathrm{m})$ & $302.2 \pm 78.9$ & $356.6 \pm 70$ & $0.009 *$ \\
\hline $1000 \mu \mathrm{m}$ superior CT $(\mu \mathrm{m})$ & $289.8 \pm 73.6$ & $352.2 \pm 70.9$ & $0.002^{*}$ \\
\hline $1500 \mu \mathrm{m}$ superior CT $(\mu \mathrm{m})$ & $278.3 \pm 79.4$ & $341.5 \pm 64.7$ & $0.009 \dagger$ \\
\hline $500 \mu \mathrm{m}$ inferior CT $(\mu \mathrm{m})$ & $285.7 \pm 81.7$ & $346 \pm 73.5$ & $0.006 *$ \\
\hline $1000 \mu \mathrm{m}$ inferior CT $(\mu \mathrm{m})$ & $280.4 \pm 73.7$ & $343.7 \pm 78.1$ & $0.003^{*}$ \\
\hline $1500 \mu \mathrm{m}$ inferior CT $(\mu \mathrm{m})$ & $275.4 \pm 78.6$ & $330.6 \pm 65.3$ & $0.007^{*}$ \\
\hline Temporal peripapillary $(\mu \mathrm{m})$ & $181.2 \pm 65.6$ & $222.8 \pm 42.5$ & $0.010^{*}$ \\
\hline Nasal peripapillary $(\mu \mathrm{m})$ & $160.3 \pm 70.4$ & $198.4 \pm 54.9$ & $0.033^{*}$ \\
\hline Superior peripapillary $(\mu \mathrm{m})$ & $176 \pm 60.2$ & $215.7 \pm 46.6$ & $0.010^{*}$ \\
\hline Inferior peripapillary $(\mu \mathrm{m})$ & $143.1 \pm 54$ & $160.8 \pm 41.8$ & $0.191 *$ \\
\hline
\end{tabular}

Notes: *Independent samples t-test; ${ }^{\dagger}$ Mann-Whitney U-test.

controls, although we did not notice any statistically significant difference in CMT and RNFL thickness in comparison to normal subjects.

Our findings regarding choroidal thickness are overall in agreement with the results of previously published studies. More specifically, El-Shazly et al demonstrated that thalassemic patients receiving two different chelation regimens (deferoxamine or deferasirox) had thinner choroids than the control group. ${ }^{9}$ Moreover, Ulusoy et al, reported that SFCT was significantly higher in controls, when comparing them to beta-thalassemia and sickle cell disease patients. ${ }^{10}$ Their results, similarly to our study, did not correlate with hemoglobin, hematocrit and serum ferritin values. Significantly lower submacular choroidal thickness has also been found in children with $\beta$-TM. In this study, a positive correlation of SFCT with hemoglobin and a negative one with ferritin levels was found. ${ }^{17}$ Comparable studies on beta-thalassemia minor, in adults and children, indicated that choroidal thickness is significantly decreased in the trait group as well. ${ }^{11,18}$

Patients with beta-thalassemia undergo hemodynamic changes and are at increased risk of vascular and thromboembolic complications. ${ }^{19,20}$ Anemia induces tissue hypoxia, ${ }^{21}$ while there is evidence of flow-mediated endothelial dysfunction. ${ }^{22}$ For instance, chronic iron overload is implicated in structural and functional changes in arteries, due to increased reactive oxygen species production through reduced nitric oxide bioavailability. ${ }^{23}$ Moreover, some authors support that frequent transfusions of stored RBCs, can affect microvascular endothelial function via a proinflammatory route. ${ }^{24}$ The above-mentioned mechanisms, along with increased platelet and RBC 
aggregation, presence of RBC membrane microparticles, erythroid cells deformities, and post-splenectomy status are some of the factors met in beta-thalassemia, that contribute to a status of hypercoagulability. ${ }^{20}$ Additionally, blood disorders, including anemia, can disrupt retinochoroidal circulation. ${ }^{25}$ Stasis, increased resistance and disturbed permeability have been associated with the development of anemic retinopathy and may equivalently affect choroidal vessels as well. ${ }^{26}$ Nonetheless, in contrast to choroidal thickness, CMT was not significantly affected in our study. This finding, in comparison to the relatively young age of the enrolled patients, may reflect a primary impairment of the choroid which may in time affect the supplied retina and retinal thickness.

We also investigated possible correlations between ocular findings and the clinical characteristics of thalassemic patients that pertain to the course of the systemic condition. Laboratory parameters like hemoglobin, serum ferritin, iron and C-reactive protein, spleen status, as well as imaging data depicting the severity of iron load in the liver and heart, estimated by $\mathrm{T} 2 *$-weighted magnetic resonance imaging, type of chelation regimen administered at the time of enrollment in the study and other comorbidities were included in our multivariable regression analysis. According to our results, patients with $\beta$-TI tended to have significantly thinner choroids than those suffering from $\beta$-TM. To our knowledge, by now there has been no comparison of choroidal thickness between the two thalassemic subgroups. A potential explanation might be that with $\beta$-TI patients the initiation of transfusions is delayed, rendering them severely anemic for a longer period of time, with an increased subsequent cardiovascular burden, including pulmonary hypertension and heart failure, conditions that are known to affect blood flow and choroidal thickness. $^{27,28}$ Furthermore, in thalassemic patients with hypothyroidism, SFCT was increased in comparison to euthyroid ones. This finding agrees with a previous study in otherwise healthy individuals with hypothyroidism. ${ }^{29}$ Regarding the chelation treatment received at the time of inclusion in the study we could not find any statistically significant correlation with CMT, RNFL thickness or SFCT.

Our study has certain limitations. Due to the small study population, as well as the frequent changes in chelation regiments and dosage over the last 5 years, according to retrospective analysis of patients' medical records, we thought it would be more indicative to classify them based on the subtype of beta-thalassemia rather than iron chelators. Although the type of chelation received at the time of enrollment was included in multivariable regression analysis, solid conclusions could not be drawn, since the majority of the patients had been exposed to different regimens in the past and the number of patients in some chelation subgroups was too small. Another limitation is that we could not predict or exclude confounders like the possible effects of accommodation and the impact of retinal image blur due to uncorrected refractive error in choroidal thickness measurements. ${ }^{30,31}$ We relied solely on pretransfusion single-point measurements. It would be interesting to also examine post-transfusion choroidal thickness. However, we decided to evade it, not to accentuate patient inconvenience. Lastly, a comparison of all three subtypes of the beta-thalassemia spectrum (ie, including carriers) to assess the effect of the severity of anemia on posterior pole structures might be of value.

\section{Conclusions}

In addition to SD-OCT for retinal disease, the application of EDI-OCT has widened the field of choroidal imaging, allowing further comprehension of its involvement in the pathophysiology of ocular disease. The outcomes of the present study along with those of the abovementioned studies, confirm that choroidal thickness is indeed reduced in all forms of beta-thalassemia. Varying RNFL and retinal thickness measurements between studies, together with contradictory evidence on correlating parameters, imply that further research and larger prospective studies may help establish the physiological relationships that might link our findings to the ocular manifestations encountered.

\section{Abbreviations}

RPE, retinal pigment epithelium; CMT, central macular thickness; RNFL, retinal nerve fiber layer; SFCT, subfoveal choroidal thickness; OCT, optical coherence tomography; SD-OCT, spectral domain optical coherence tomography; EDI-OCT, enhanced depth imaging optical coherence tomography; $\beta$-TM, beta-thalassemia major; $\beta$-TI, betathalassemia intermedia; TD- $\beta$-thal, transfusion-dependent beta-thalassemia; RBC, red blood cell; BCVA, best corrected visual acuity; IOP, intraocular pressure.

\section{Disclosure}

Alexandra Kouraklis reports personal fees from Abbvie, outside the submitted work. Argiris Symeonidis reports grants and personal fees from Abbvie, personal fees from BMS and Novartis, outside the submitted work. The authors report no other potential conflicts of interest in this work. 


\section{References}

1. Loukopoulos D. Haemoglobinopathies in Greece: prevention programme over the past 35 years. Indian J Med Res. 2011;134 (4):572-576.

2. De Virgiliis S, Congia M, Turco MP, et al. Depletion of trace elements and acute ocular toxicity induced by desferrioxamine in patients with thalassaemia. Arch Dis Child. 1988;63(3):250-255. doi:10.1136/adc.63.3.250

3. Taneja R, Malik P, Sharma M, Agarwal MC. Multiple transfused thalassemia major: ocular manifestations in a hospital-based population. Indian J Ophthalmol. 2010;58(2):125-130. doi:10.4103/ 0301-4738.60083

4. Jafari R, Heydarian S, Karami H, et al. Ocular abnormalities in multi-transfused beta-thalassemia patients. Indian $J$ Ophthalmol. 2015;63(9):710-715. doi:10.4103/0301-4738.170986

5. Sugiyama T, Araie M, Riva CE, Schmetterer L, Orgul S. Use of laser speckle flowgraphy in ocular blood flow research. Acta Ophthalmol. 2010;88(7):723-729. doi:10.1111/j.1755-3768.2009.01586.x

6. Parver LM. Temperature modulating action of choroidal blood flow. Eye (Lond). 1991;5(Pt 2):181-185. doi:10.1038/eye.1991.32

7. Ikuno Y, Kawaguchi K, Nouchi T, Yasuno Y. Choroidal thickness in healthy Japanese subjects. Invest Ophthalmol Vis Sci. 2010;51 (4):2173-2176. doi:10.1167/iovs.09-4383

8. Tan CS, Ouyang Y, Ruiz H, Sadda SR. Diurnal variation of choroidal thickness in normal, healthy subjects measured by spectral domain optical coherence tomography. Invest Ophthalmol Vis Sci. 2012;53 (1):261-266. doi:10.1167/iovs.11-8782

9. El-Shazly AA, Elkitkat RS, Ebeid WM, Deghedy MR. Correlation between subfoveal choroidal thickness and foveal thickness in thalassemic patients. Retina. 2016;36(9):1767-1772. doi:10.1097/ IAE.0000000000000970

10. Ulusoy MO, Türk H, Kıvanç SA. Spectral domain optical coherence tomography findings in Turkish sickle-cell disease and beta thalassemia major patients. J Curr Ophthalmol. 2019;31(3):275-280. doi:10.1016/j.joco.2019.01.012

11. Arifoglu HB, Kucuk B, Duru N, et al. Assessing posterior ocular structures in $\beta$-thalassemia minor. Int Ophthalmol. 2018;38 (1):119-125.

12. Sizmaz S, Küçükerdönmez C, Pinarci EY, Karalezli A, Canan H, Yilmaz G. The effect of smoking on choroidal thickness measured by optical coherence tomography. $B r \quad J$ Ophthalmol. 2013;97 (5):601-604. doi:10.1136/bjophthalmol-2012-302393

13. Yamashita T, Yamashita T, Shirasawa M, Arimura N, Terasaki H, Sakamoto T. Repeatability and reproducibility of subfoveal choroidal thickness in normal eyes of Japanese using different SD-OCT devices. Invest Ophthalmol Vis Sci. 2012;53(3):1102-1107. doi:10.1167/iovs.11-8836

14. Lou L, Ostrin LA. Effects of narrowband light on choroidal thickness and the pupil. Invest Ophthalmol Vis Sci. 2020;61(10):40. doi:10.1167/iovs.61.10.40

15. Vural AD, Kara N, Sayin N, Pirhan D, Ersan HB. Choroidal thickness changes after a single administration of coffee in healthy subjects. Retina. 2014;34(6):1223-1228. doi:10.1097/IAE.0000000000000043
16. Simsek A, Tekin M, Bilen A, Karadag AS, Bucak IH, Turgut M. Evaluation of choroidal thickness in children with iron deficiency anemia. Invest Ophthalmol Vis Sci. 2016;57(14):5940-5944. doi:10.1167/iovs.15-18713

17. Simsek A, Tekin M, Bilak S, Karadag AS, Konca C, Almis H. Choroidal thickness in children with beta thalassemia major. Optom Vis Sci. 2016;93(6):600-606. doi:10.1097/OPX.0000000000000833

18. Acer S, Balc1 YI, Pekel G, et al. Retinal nerve fiber layer thickness and retinal vessel calibers in children with thalassemia minor. $S A G E$ Open Med. 2016;2(4):2050312116661683.

19. Morris CR. Mechanisms of vasculopathy in sickle cell disease and thalassemia. Hematology Am Soc Hematol Educ Program. 2008;2008:177-185. doi:10.1182/asheducation-2008.1.177

20. Cappellini MD, Musallam KM, Marcon A, Taher AT. Coagulopathy in beta-thalassemia: current understanding and future perspectives. Mediterr J Hematol Infect Dis. 2009;1(1):e2009029.

21. Haase VH. Regulation of erythropoiesis by hypoxia-inducible factors. Blood Rev. 2013;27(1):41-53. doi:10.1016/j.blre.2012.12.003

22. Hahalis G, Kremastinos DT, Terzis G, et al. Global vasomotor dysfunction and accelerated vascular aging in beta-thalassemia major. Atherosclerosis. 2008;198(2):448-457. doi:10.1016/j. atherosclerosis.2007.09.030

23. Ribeiro Júnior RF, Marques VB, Nunes DO, Stefanon I, Dos Santos L. Chronic iron overload induces functional and structural vascular changes in small resistance arteries via NADPH oxidase-dependent O2- production. Toxicol Lett. 2017;279:43-52. doi:10.1016/j.toxlet.2017.07.497

24. Parviz Y, Hsia C, Alemayehu M, et al. The effect of fresh versus standard blood transfusion on microvascular endothelial function. $\mathrm{Am}$ Heart J. 2016;181:156-161. doi:10.1016/j.ahj.2016.05.021

25. Kacer B, Hattenbach LO, Hörle S, Scharrer I, Kroll P, Koch F. Central retinal vein occlusion and nonarteritic ischemic optic neuropathy in 2 patients with mild iron deficiency anemia. Ophthalmologica. 2001;215(2):128-131. doi:10.1159/000050843

26. Loewenstein JI. Retinopathy associated with blood anomalies. Clin Ophthalmol. 1995;3(85):995-1000.

27. Aessopos A, Farmakis D, Deftereos S, et al. Thalassemia heart disease: a comparative evaluation of thalassemia major and thalassemia intermedia. Chest. 2005;127(5):1523-1530. doi:10.1378/ chest.127.5.1523

28. Yeung SC, You Y, Howe KL, Yan P. Choroidal thickness in patients with cardiovascular disease: a review. Surv Ophthalmol. 2020;65 (4):473-486. doi:10.1016/j.survophthal.2019.12.007

29. Ulas F, Ü D, Dikbas O, Celebi S, Keles A. Investigation of the choroidal thickness in patients with hypothyroidism. Indian J Ophthalmol. 2015;63(3):244-249. doi:10.4103/0301-4738.156976

30. Woodman-Pieterse EC, Read SA, Collins MJ, Alonso-Caneiro D. Regional changes in choroidal thickness associated with accommodation. Invest Ophthalmol Vis Sci. 2015;56 (11):6414-6422. doi:10.1167/iovs.15-17102

31. Hoseini-Yazdi H, Vincent SJ, Collins MJ, Read SA. Regional alterations in human choroidal thickness in response to short-term monocular hemifield myopic defocus. Ophthalmic Physiol Opt. 2019;39 (3):172-182.
Clinical Ophthalmology

\section{Publish your work in this journal}

Clinical Ophthalmology is an international, peer-reviewed journal covering all subspecialties within ophthalmology. Key topics include: Optometry; Visual science; Pharmacology and drug therapy in eye diseases; Basic Sciences; Primary and Secondary eye care; Patient Safety and Quality of Care Improvements. This journal is indexed on PubMed
Central and CAS, and is the official journal of The Society of Clinical Ophthalmology (SCO). The manuscript management system is completely online and includes a very quick and fair peer-review system, which is all easy to use. Visit http://www.dovepress.com/ testimonials.php to read real quotes from published authors.

\section{Dovepress}

